\title{
Safety Management in Sustainable Construction Projects: A Conceptual Framework
}

\author{
Afaf Hassan \\ Dept. of Environmental Health and Safety, Abu Dhabi University \\ PO Box 5911, Abu Dhabi, United Arab Emirates \\ Tel: 971-2501-5555Ｅ-mail: afaf.hassan@adu.ac.ae
}

Received: August 2, 2021 Accepted: September 30, $2021 \quad$ Published: October 3, 2021

doi:10.5296/ijgs.v5i1.19061ＵRL: https://doi.org/10.5296/ijgs.v5i1.19061

\begin{abstract}
Safety management can be utilized effectively in sustainable construction projects, to produce safe sustainable construction projects. This highlights the necessity to gain a better understanding about safety management components with a view to pinpointing existing and future research issues to be addressed. Thus, this systematic review aims to demonstrate a knowledge base for safety management research grounded on the safety management components, and the integration of those components into sustainable construction projects, to produce safe sustainable construction projects. To achieve this, thirty-four peer-reviewed articles were classified into two categories. The first category is about safety management in typical construction projects, and the second category is about safety management in sustainable construction projects. Similar research in the last two decades points out the challenges associated with safety management in sustainable construction projects and the need to understand the associated safety management components that can lead to safer suitable construction projects. In addition, the synthesis suggests the need for a conceptual framework that explains the process of utilizing safety management components in sustainable construction projects to attain the desired safety outcomes in sustainable construction projects. Accordingly, this article provides a conceptual framework that integrates safety management components of traditional construction projects into sustainable construction projects, to achieve safe sustainable construction projects.
\end{abstract}

Keywords: Safety management, Sustainable development, Construction projects

\section{Introduction}

"Construction is one of the most hazardous industries due to its dynamic, temporary, and decentralized nature" (Li et al., 2015, p.107). Construction projects' considerable risks for the 


\section{$\triangle$ Macrothink}

society, economy, and the environment have been well recognized ever since construction projects were initiated (Grote, 2012; Lee \& Son, 2021). In line with this argument, Loushine et al. (2006) have pointed out that construction has always been considered a dangerous work environment. Construction projects also have their problems and risks, especially the complicated structure, volume, and mechanism, which critically enhance the structural design as well as site and construction technologies ( $\mathrm{Li}$ et al., 2021). At the same time, the construction period of complicated or large construction projects is long, the working environment is tough, and a large amount of workload and working procedures could produce safety hazards (Li et al., 2021; Lee \& Son, 2021). Yet, the fatal accident rate in construction projects tends to be more than that of any other industry (Park \& Hyeon-Jin, 2013). In turn, this created a need to mitigate these risks to achieve safe construction projects (Grote, 2012).

El-Sayegh et al. (2018) defined sustainable construction projects as any projects that cover a sustainable: design, construction, and operation. They also added that sustainable construction is about producing green building projects in which attaining sustainability is one of the main targets. Later, Udomsap and Hallinger (2020) described sustainable construction projects as any construction projects that create and operate a healthy build environment through utilizing ecological principles and natural resources' efficiency. Whereas Zhang et al. (2020) clarified that the concept of sustainable construction is driven by sustainability science that aims to produce a green environment, to maintain and enhance human development as well as survival. Hence, sustainable construction projects are directed towards maximizing the use of renewable resources, minimizing the production of pollutants, and mitigating any harmful impacts that could influence human health (Gunduz \& Almuajebh, 2020; Tahmasebinia et al., 2020; Zhang et al., 2020). In other words, sustainable construction adopts and applies sustainability ideas to direct the construction and operation tasks during the whole life cycle of a typical construction project (Tahmasebinia et al., 2020; Udomsap \& Hallinger, 2020; Zhang et al., 2020). However, like the traditional construction projects, sustainable construction projects range from medium to large and vary depending on the complexity, size, and duration of such projects (Gharehbaghi \& McManus, 2003; Heravi \& Faeghi, 2014; Lee \& Son, 2021). This implies that achieving efficient safety management in such projects is not only challenging but also very complicated (Gunduz \& Almuajebh, 2020; Tahmasebinia et al., 2020; Udomsap \& Hallinger, 2020; Zhang et al., 2020). Consequently, a higher level of safety management would be required in such projects (Wu et al., 2017). In support, Okoye and Okolie (2013) mentioned that safe sustainable construction could only be attained through education and training, attitudinal change, beliefs, management commitment, perceptional change, and workers involvement (Liwång, 2020; Okoye, 2010; Tahmasebinia et al., 2020). Safe sustainable construction practices also require adequate consideration of the economic, social environmental, and political imperatives (Gunduz \& Almuajebh, 2020; Okoye \& Okolie, 2013; Tahmasebinia et al., 2020; Liwång, 2020; Wu et al., 2017). In other words, safe sustainable construction projects adopt more than just the traditional process of constructing structures and buildings sustainably, yet it should cover means that both the process and products become seen with sustainable backward and forward linkages (Gunduz \& Almuajebh, 2020; Liwång, 2020; Okoye \& Okolie, 2013; Tahmasebinia et al., 2020). 


\section{Macrothink}

Considering the arguments about the effectiveness of safety management in sustainable construction projects (Grote, 2012; Kukoyi \& Adebowale, 2021; Loushine et al., 2006; Marhavilas et al., 2018; Okoye \& Okolie, 2013; Zacchei \& Molina, 2020), the question on how to apply safety management components of tradition construction projects in sustainable construction project gains increased importance. The reason is that the relevant research in the last two decades has substantially discussed successful safety management in traditional construction projects (Kim et al., 2020; Kukoyi \& Adebowale, 2021; Lee \& Son, 2021; Li et al., 2015; Liwång, 2020), but did not address, efficiently, the issue of safety management in sustainable construction projects (Li et al., 2021; Loushine et al., 2006; Marhavilas et al., 2018; Okoye \& Okolie, 2013; Robichaud \& Anantatmula, 2011; Zacchei \& Molina, 2020) Therefore, this research will fill this gap by constructing a conceptual framework that aims to integrate safety management in sustainable construction projects, to produce safe sustainable construction projects. In particular, this systematic review will investigate the essential safety management components that are needed to produce safe sustainable construction projects, and illustrate the research outcome in an effective conceptual framework.

\section{Method}

This research adopted the systematic review approach established by Petticrew and Roberts (2006). Mainly, the review relied on peer-reviewed literature published in international scientific journals. The key terms, such as safety management and sustainable construction, were used to find the relevant articles from Google Scholar. The searches in Google Scholar database yielded a total of forty peer-reviewed articles. These articles were screened by the author. To specify the analysis, the inclusion criteria were focused on articles discussing safety management in both traditional and sustainable construction projects.

Accordingly, the author read the abstracts of each article thoroughly and, if the paper is closely related to the topic of the research, the author continued reading the methodology and conclusions to assure that the article fulfilled all inclusion criteria. Articles that were found to be irrelevant were filtered and removed. Furthermore, the systematic review checklist established by Moher et al. (2009) was used. This checklist includes four main criteria that are identifying, screening, assuring eligibility, and deciding articles to be included (Moher et al., 2009). Hence, the author initially identified the forty related articles through manual search using Google Scholar. Then, some articles were excluded after closely checking the content and finding it to be irrelevant. The remaining full-text articles were assessed for eligibility. This reduced the sample of studies from forty to thirty-four journal articles.

These thirty-four peer-reviewed articles were also used to establish the conceptual framework of this study. The framework integrated the information, arguments, and findings of these articles to create a new integrative framework that covers five main stages that are (1) safety management components, (2) safety management input, (3) sustainable construction projects' surrounding factors, (4) safety management output, and (5) safe sustainable construction projects, respectively. Ultimately, the valuable knowledge and information obtained from these articles had been used to satisfy the main purpose of this research, which is introducing an effective framework to adopt and implement effective safety management in sustainable construction projects, to achieve safe sustainable construction projects. 


\section{Literature Review}

\subsection{Safety Management in Construction Projects}

\subsubsection{Safety Management}

Safety management has been defined as a promotion of good safety performance and safety culture (Grote, 2012). It has also been recognized as the use safety components to manage safety policy; safety resources and responsibilities; risk identification and mitigation; standards and procedures; human factors-based system design; safety training; safety performance monitoring; incident reporting and investigation; auditing; continuous improvement; and change (Grote, 2012; Kukoyi \& Adebowale, 2021; Lee \& Son, 2021). These components should not only be seen as general standards but also be included in any safety management system (Grote, 2012). At a later stage, safety management has been promoted as effective safety behaviors and practices (Okoye \& Okolie, 2013). In other words, the safety management process must be well planned to enable construction site managers as well as workforces to not only identify and identify safety risks but also communicate effectively with each other during the construction processes (Kukoyi \& Adebowale, 2021; Lee \& Son, 2021; Park \& Hyeon-Jin, 2013). Moreover, Yiu et al. (2018) have identified safety management to be the management of all functions associated with carrying on activities relates to the safety of personnel including organizing, planning, developing, and implementing safety policy. They have also added that the efficiency of safety management can be measured using regular audits and reviews of performance.

\subsubsection{Safety Management in Construction Projects}

In traditional construction sites, safety has required more hours of staff time than in any other setting (Kim et al., 2020; Kukoyi \& Adebowale, 2021; Lee \& Son, 2021; Li et al., 2015; Liwång, 2020). The reason is that workers are likely to keep moving from one place to another to complete their work on construction sites, and thus it could be difficult to identify and track the possible hazards as well as the likelihood of their occurrence (Kim et al., 2020; Li et al., 2015; Lee \& Son, 2021; Liwång, 2020). It is also essential to recognize that each construction site has its accident rate (Yiu et al., 2018). In turn, this raises the importance of safety on such sites, to protect involved individuals from harm, or at least, reduce the rate of accidents linked to construction projects. In this concern, it has been argued that most of the accidents on construction sites could have been minimized and prevented with the adoption of consistent and adequate safety management: process, plan, education, training, and inspection (Kim et al., 2020; Kukoyi \& Adebowale, 2021; Liwång, 2020; Park \& Hyeon-Jin, 2013). This drives the attention to the concept of safety management, as effective safety management reduces the likelihood of occurrence and the severity of any non-planned events or incidents, which could cause harm to project team members (Kukoyi \& Adebowale, 2021; Lee \& Son, 2021; Liwång, 2020; Loushine et al., 2006).

The right process and methods should be followed to conduct effective safety management in construction projects (Kukoyi \& Adebowale, 2021; Liwång, 2020). Prior research has limited safety management in construction to be about planning, education, and inspection phases 
(Kim et al., 2020; Park \& Hyeon-Jin, 2013). Later, critical issues have been considered in safety management such as the identification of activity-specific safety risks and how each one of them could be delivered; and the other one is effective communication with the workers at the construction site (Kukoyi \& Adebowale, 2021; Lee \& Son, 2021; Liwång, 2020; Park \& Hyeon-Jin, 2013). Li et al. (2015) have suggested that new methods have been initiated and implemented to improve safety management in construction projects, which include hazard identification, safety training, and safety data recording. Li et al. (2015) have also added that nine factors could impact safety management at construction sites, which are safety management, perceived risk, working environment, productivity pressure, self-efficacy, self-esteem, Personal Protection Equipment (PPE) use, training and exchange, and safety attitude. This indicates that a well-trained safety management staff, could reduce the overhead of safety management and greatly enhance safety management effectiveness (Kim et al., 2020; Li et al., 2015). This was supported by the argument of Ladewski and Al-Bayati (2019), who has emphasized that safety management methods could take two directions. First, managing safety through concentrating on meeting local and international technical and training standards to avoid enforcement actions and penalties. Second, managing safety through self-correction could be achieved either through identifying and reporting hazards or through corrective actions to unsafe behaviors (Kukoyi \& Adebowale, 2021; Ladewski \& Al-Bayati, 2019; Lee \& Son, 2021; Liwång, 2020). Ultimately, Yiu et al. (2018) have mentioned that safety audits and reviews are common safety assessment tools, that could lead to a positive outcome in construction projects.

\subsection{Sustainable Construction Projects}

\subsubsection{Sustainable Construction}

Like sustainable development projects, "Sustainable construction therefore is the construction that tows the principles of sustainable development" (Okoye \& Okolie, 2013, p.78). Other scholars have also emphasized that sustainable construction entails three key dimensions that are economic growth, social equity, and environmental protection, and as a reflection, these issues are related to sustainable development (Mensah et al., 2018; Okoye \& Okolie, 2013; Udomsap \& Hallinger, 2020). In support, Wu et al. (2017) have pointed out that sustainable construction has been recognized as the construction activities that meet the demands of sustainable development. They have also added that it could be described as an attempt to ensure social health and economic development at the same time as reducing any possible negative impacts of construction on the environment (Wu et al., 2017; Tahmasebinia et al., 2020). These arguments indicate that sustainable construction is an essential part of sustainable development. Over time, sustainability has referred to "people-centered development and ending poverty and distributional equity as key objectives; structural transformation of national economies and reforms in global economic governance to create an enabling environment for development" (Fukuda-Parr \& Muchhala, 2020, p.104706). However, in this study, sustainable construction is operationalized as the implementation of sustainable development principles to construction projects through safety management (Mensah et al., 2018). This indicates the importance of studying safety management in sustainable construction projects. 


\section{Macrothink}

International Journal of Global Sustainability

ISSN 1937-7924

2021, Vol. 5, No. 1

Sustainable construction has considerable benefits on the environment, society, and economy (Gunduz \& Almuajebh, 2020; Udomsap \& Hallinger, 2020; Tahmasebinia et al., 2020) An adequate sustainable construction leads to successful sustainable development (Okoye \& Okolie, 2013). The reason is that sustainable construction is considered a driver to all facets of sustainable development processes (Okoye \& Okolie, 2013). Sustainable construction tends to create and operate a healthy built environment based on resource proficiency and environmental design with a focus on seven principles for a safer construction that is protecting nature, eliminating toxins, applying life cycle costing, reducing resource consumption, reusing resources, using recyclable resources, and concentrating on quality (Robichaud \& Anantatmula, 2011). Another positive outcome of sustainable construction is collaborating effectively to complete all tasks and activities successfully (Wu et al., 2017). This could be achieved through strengthening resource integration capability and building effective communication mechanisms (Gunduz \& Almuajebh, 2020; Tahmasebinia et al., 2020; Wu et al., 2017). This highlights the prominence of awareness, knowledge, demand, commitment, implementation, and communication among project team members as well as management (Wu et al., 2017). Recently, sustainable construction has been focused on reducing the consumption of natural resources (e.g., electricity and water) and emphasizing the use of recycled and preferably non-toxic raw materials (Afanasyeva et al., 2020).

\subsubsection{Sustainable Construction Projects}

Sustainable construction projects have not received considerable attention; thus, it might not be easy to find a precise definition that explains it accurately in terms of the possible changes and associated hazards (Ciegis et al., 2011, Gunduz \& Almuajebh, 2020; Tahmasebinia et al., 2020). Likewise, the practical aspects of sustainable construction in recent projects have not been actively adopted nor implemented (Afanasyeva et al., 2020). In clarification, sustainable construction projects could be completed successfully, only if there is an improvement in three main pillars of sustainability that are economic, social, and environmental (Ciegis et al., 2011; Gunduz \& Almuajebh, 2020; Zhang et al., 2020). In this regard, Sachs (2012) have stated that although sustainable construction projects are designed to combine environmental protection, economic development, and social inclusion, the definitions of sustainable construction projects will differ, as the specific objectives are different worldwide, not only between societies but also within them (Tahmasebinia et al., 2020; Udomsap \& Hallinger, 2020; Zhang et al., 20200. On the other hand, most of the definitions emphasize the existence of a relationship between construction and sustainability (Gunduz \& Almuajebh, 2020; Tahmasebinia et al., 2020; Zhang et al., 2020). In justification, Sustainable development projects are projects that are designed to expand the opportunity of existing generations to satisfy their needs without compromising the capability of future generations to satisfy their needs as well (Remington-Doucette \& Musgrove, 2015). Sustainable construction projects also stand for projects that meet the present needs without limiting the possibility of meeting the future needs (Tahmasebinia et al., 2020; Wu et al., 2017). Besides, many other scholars have agreed that sustainable construction projects are sustainability project have common goals that are protecting the environment, maintaining social equity, and improving the economy (Gunduz \& Almuajebh, 2020; Tahmasebinia et al., 2020). Researchers have also 


\section{MInstitute ${ }^{\text {Macrothink }}$}

highlighted that sustainable construction projects are any projects that respond to current and future problems such as climate change, desertification, pandemics, and poverty, that are commonly featuring high degrees of uncertainty, complexity urgency, and damage potential (Gunduz \& Almuajebh, 2020; Udomsap \& Hallinger, 2020; Wiek et al., 2011; Zhang et al., 2020). Lately, Secundo et al. (2020) have stated that sustainable development projects are projects that cover a wide range of social, environmental, and economic issues, entailing energy, biodiversity, gender, equality, climate change, peace, security, food supply, economic growth, healthcare, education, sustainable consumption, and sustainable production. They have elaborated that the main goal of sustainable development projects is to find out efficient solutions for new challenges such as climate change, food security, ecosystem resilience, energy, pollution, migration, and many other matters that demand a cross-disciplinary standpoint (Secundo et al., 2020; Tahmasebinia et al., 2020; Udomsap \& Hallinger, 2020; Zhang et al., 2020). Considering the above argument, this study defines sustainable construction projects as any projects that complete construction activities with full respect to the main pillar of sustainability that are environmental protection, economic growth, and social equity (Gunduz \& Almuajebh, 2020; Tahmasebinia et al., 2020; Zhang et al., 2020).

Furthermore, sustainable construction projects have recently experienced significant growth (Robichaud \& Anantatmula, 2011). The reason is that the public is becoming aware of the benefits of such projects for the economy, society, and the environment (Robichaud \& Anantatmula, 2011). In other words, sustainable construction has a major role to play in terms of the sustainable development of various societies (Okoye \& Okolie, 2013). However, in comparison with traditional construction projects, sustainable construction projects demand a higher level of collaboration amongst project team members and management (Gunduz \& Almuajebh, 2020; Udomsap \& Hallinger, 2020; Wu et al., 2017; Zhang et al., 2020). Individuals working in the construction field intend to maintain mutual collaboration in a way that reduces associated risk, restricts costs, and increases benefits (Ginevičius et al., 2011). The reason is that designs, systems, and technologies associated with sustainable construction are usually found to be complex and not straightforward to work with (Wu et al., 2017). This drives project team members and management of such projects to pursue an effective sustainable construction with ethical motives and willingness to attain a high level of professionalism (Wu et al., 2017). That is why, encouraging and attaining the adoption and implementation of sustainable construction projects is the main concern of several recent studies (Gunduz \& Almuajebh, 2020; Tahmasebinia et al., 2020; Udomsap \& Hallinger, 2020; Wu et al., 2017; Zhang et al., 2020).

Nevertheless, some factors critically influence sustainable construction projects (Gunduz \& Almuajebh, 2020; Tahmasebinia et al., 2020; Zhang et al., 2020). In this concern, Robichaud and Anantatmula (2011) have summarized some factors that impact sustainable construction projects such as the increase: energy prices, costs of construction materials, and regulatory incentives, which are pushing the interest in sustainable construction projects to grow and expand. Okoye and Okolie (2013) have mentioned that the social aspects of suitable construction projects are concerned about the moral, legal, and ethical obligations of sustainable construction projects to their stakeholders. They have also elaborated that socially 
sustainable construction cannot be achieved without an adequate corresponding behavior and attitudinal change towards safety in construction projects. The reason is that, for sustainable construction that is socially efficient, health and safety should always be at the forefront (Okoye \& Okolie, 2013). On top of this, the social aspect of sustainable construction entails workers' health and safety; quality of life and benefits to the disadvantaged groups; and impacts on local communities (Okoye \& Okolie, 2013; Tahmasebinia et al., 2020). This creates an effective involvement of societies that facilitates the needed improvements to take place (Boyd \& Bentley, 2012). In other words, the social aspects of sustainable construction projects are considered as a compilation of efforts and actions to enhance development, which does not deplete the stock of human and social resources but rather encourages and contributes to the advancement of their potentials (Gunduz \& Almuajebh, 2020; Okoye \& Okolie, 2013; Zhang et al., 2020). This means that sustainable construction could be enhanced through motivating project teams and improving their social skills (Hewage et al., 2011). From an economical point of view, Robichaud and Anantatmula (2011) have argued that competent project management could help in delivering sustainable construction projects within acceptable cost constraints (Robichaud \& Anantatmula, 2011). Other scholars have supported both the social and economic aspects that impact sustainable construction projects, as such projects embrace sustainable design, community development in addition to the health, safety, and welfare of workers in the project (Afanasyeva et al., 2020; Mensah et al., 2018; Okoye \& Okolie, 2013; Udomsap \& Hallinger, 2020; Zhang et al., 2020). It is also important to recognize that many barriers, to the achievement of safety management in sustainable construction, continue to exist due to cost constraints (Robichaud \& Anantatmula, 2011). As a result, better employment opportunities would be available for society and, in turn, more economic growth (Gunduz \& Almuajebh, 2020; Udomsap \& Hallinger, 2020; Zhang et al., 2020). This implies that economic growth is the main concern of sustainable construction projects. In addition, Li et al. (2021) have argued that some factors affect sustainable construction projects, which are the long project period, harsh environment, complex process, and the dynamism of the large work. This points out that the importance of protecting the environment from the start-up to the completion of any sustainable construction project.

\subsection{Safety Management in Sustainable Construction Projects}

In the face of the numerous recent safety challenges and the widely spread unsustainable safety management, safe sustainable construction projects are highly demanded (Kukoyi \& Adebowale, 2021; Marhavilas et al., 2018; Okoye \& Okolie, 2013; Zacchei \& Molina, 2020). In justification, safety management for sustainable construction projects involves people, objects, construction environment, and numerous safety management processes (Kukoyi \& Adebowale, 2021; Li et al., 2021; Liwång, 2020). This does not only increase the likelihood of safety incidents occurring but also the need for efficient safety management in construction projects. In support, Grote (2012) has mentioned that is important to understand that sustainable construction projects could have relatively large potential for major accidents, or minor occupational accidents depending on the type and size of a project. Also, the increasing complexity of sustainable construction projects makes the traditional construction safety 
management tools inefficient (Kukoyi \& Adebowale, 2021; Li et al., 2021; Liwång, 2020; Marhavilas et al., 2018; Zacchei \& Molina, 2020). On the other side, the rising awareness of sustainable construction's ability to positively impact environmental issues is increasing the need for adequate safety management to the forefront (Robichaud \& Anantatmula, 2011; Marhavilas et al., 2018; Zacchei \& Molina, 2020). These facts have created a need for modern safety management that helps in completing sustainable construction projects without, or with fewer, safety incidents (Kukoyi \& Adebowale, 2021; Li et al., 2021; Liwång, 2020; Zacchei \& Molina, 2020).

Adopting and implementing adequate safety management is crucial for sustainable development projects. In justification, successful safety management leads to better sustainable construction environmental qualities; a greater degree of housekeeping; better employee selection procedures; more frequent use of lead workers performing training; and a stable workforce (Loushine et al., 2006; Marhavilas et al., 2018; Zacchei \& Molina, 2020). Loushine et al. (2006) have added that advances in safety and health management research have introduced new perceptions in safety management that include, but are not limited to, a safe climate, behavioral safety, safety culture, and human error theory. This drives the attention that the main safety management outcomes to be reduced injury and fatality incidence rates; reduced costs associated with injuries/fatalities; and reduced workers' compensation insurance premiums. The 'human element', or in other words the society, should always be addressed when discussing safety management in sustainable construction projects (Kukoyi \& Adebowale, 2021; Liwång, 2020; Loushine et al., 2006; Zacchei \& Molina, 2020). In addition, Okoye and Okolie (2013) have found out that efficient safety management utilizes an effective management commitment to construction safety concerns. This implies that effective safety management, in sustainable construction projects, is relatively linked to the management level. The reason is that if the sustainable construction personnel couldn't be successfully educated, guided, and managed, safety incidents could easily be induced (Li et al., 2021; Liwång, 2020; Marhavilas et al., 2018). However, with the progress of the social economy, the social infrastructure sustainable construction has achieved observable growth, particularly the appearance of numerous types of sustainable construction projects, which requires the safety management level to be improved, to ensure the safety and reliability of sustainable construction projects (Li et al., 2021; Liwång, 2020; Marhavilas et al., 2018; Zacchei \& Molina, 2020).

To understand safety management in sustainable construction projects, it is essential to study the main risk factors and problems in such projects (Li et al., 2021; Zacchei \& Molina, 2020). In their conceptual framework, Loushine et al. (2006) have found out that the main safety management elements in sustainable construction projects are management commitment; employee involvement; hazard identification and control; training and education; accident investigation; and housekeeping effort. Grote (2012) has highlighted three attributes that affect the various ways safety management should be designed, run, and evaluated. These attributes are the type of safety, the method used to manage associated uncertainty, and the existing safety regulations. Recently, risk factors could include project complexity, human, material, and environmental factors (Li et al., 2021; Marhavilas et al., 2018; Zacchei \& 
Molina, 2020). In explanation, the complexity of the project engineering, poor safety management, and unreliable safety management techniques could easily cause accidents in sustainable construction projects (Kukoyi \& Adebowale, 2021; Li et al., 2021; Liwång, 2020). Human factors include safety accidents or other dangers resulted from non-standard operations that could be performed by some construction personnel (Li et al., 2021; Marhavilas et al., 2018; Zacchei \& Molina, 2020). Material factor, similar to typical construction, the sustainable construction materials cover construction tools, building materials, and engineering equipment and machinery. The destructive properties of these substances lay the material premise of the accident. If such materials are not used in a standard way, they could be very dangerous and easily course accidents (Li et al., 2021; Liwång, 2020; Zacchei \& Molina, 2020). Environment factors of sustainable construction projects involve natural social and work environment dimensions. Although this could be a neglected factor most of the time, sustainable construction environmental factors easily produce safety accidents (Li et al., 2021; Marhavilas et al., 2018; Zacchei \& Molina, 2020).

Overall, earlier research has given a noticeable focus on safety management in traditional construction projects (Kukoyi \& Adebowale, 2021; Lee \& Son, 2021; Liwång, 2020; Loushine et al., 2006). It was highlighted that the construction field is very hazardous and needs imperative concentration on safety issues, to reduce (or if possible avoid) any possible and repeating safety incidents that can produce human, economic, and environmental losses (Kim et al., 2020; Kukoyi \& Adebowale, 2021; Lee \& Son, 2021; Li et al., 2015; Liwång, 2020; Loushine et al., 2006). Similarly, scholars have agreed that sustainable construction projects incorporate several hazards that can lead to numerous safety incidents (Loushine et al., 2006; Marhavilas et al., 2018; Robichaud \& Anantatmula, 2011; Zacchei \& Molina, 2020). In justification, the sustainable construction projects are new and some of them are being applied for the first time (Gunduz \& Almuajebh, 2020; Tahmasebinia et al., 2020; Udomsap \& Hallinger, 2020; Wu et al., 2017; Zhang et al., 2020), this can produce unexpected or unexperienced safety accidents. Thus, it is not only essential to conduct a systematic review about safety management components that work effectively in sustainable construction projects but also illustrated the findings in a conceptual framework.

\section{Conceptual Framework for Safety Management in sustainable Construction Projects}

A flexible framework should be established to demonstrate the main components and aspects of safety management that could lead to an adequate adoption and implementation of safe sustainable construction projects (Yiu et al., 2018). Given that a "safe sustainable construction project" refers to any construction project that adopts the pillars of sustainability (environmental protection, economic growth, and social equity) within its objectives, and applies safety management effectively to avoid or reduce accidents (Grote, 2012; Kim et al., 2020; Liwång, 2020; Loushine et al., 2006; Wu et al., 2017; Marhavilas et al., 2018; Zacchei \& Molina, 2020; Zhang et al., 2020).

This study integrates the safety management components established by Grote (2012), the safety management input proposed by Loushine et al. (2006); the surrounding factors in sustainable construction projects; the pillars of sustainability highlighted by numerous 
scholars; and the safety outcomes suggested by Loushine et al. (2006) in a conceptual framework to produce safe suitable construction projects. First, the main components of safety management in construction projects are compliance with local and international safety policies; selecting adequate safety resources and specifying their responsibilities; identifying and mitigating risks; following safety standards and procedures; coping with human safety factors using effective system designs; training employees; monitoring safety performance; repotting and investigating incidents; auditing; seeking continuous developments; and managing change (Grote, 2012; Liwång, 2020; Marhavilas et al., 2018; Zacchei \& Molina, 2020). Second, the components suggested by Grote (2012) are used to shape an effective safety management input. In detail, the management input includes a robust management commitment towards safety; effective involvement of employees; accurate hazard identification and control; well-educated and trained employees; efficient accident investigation; and meaningful efforts in housekeeping to generate and maintain safety (Kukoyi \& Adebowale, 2021; Liwång, 2020; Loushine et al., 2006; Marhavilas et al., 2018; Zacchei \& Molina, 2020). Third, the safety management input provided by Loushine et al. (2006) is merged with the surrounding factors of sustainable construction projects. In turn, this leads to substantial improvements in sustainable construction projects such as better communication among project team members; broad awareness about safety procedures and policies; advanced knowledge about risk identification, investigation, monitoring, and controlling; higher demand for more safe sustainable construction projects; commitments to deliver safe projects; and successful implementation the sustainable construction project considering the safety components and safety management inputs (Grote, 2012; Kukoyi \& Adebowale, 2021; Liwång, 2020; Loushine et al., 2006; Wu et al., 2017; Marhavilas et al., 2018; Zacchei \& Molina, 2020). Forth, the combination of safety management input with the surrounding factors of sustainable development projects creates a desired safety management output in sustainable construction projects. This safety management output includes reduced injury and fatality incidence rate; minimized injury/fatality costs; and reduced workers' compensation insurance premiums (Kukoyi \& Adebowale, 2021; Liwång, 2020; Loushine et al., 2006; Marhavilas et al., 2018; Zacchei \& Molina, 2020). Ultimately, the integration of these four steps produces safe sustainable construction projects as shown in Figure 1. 


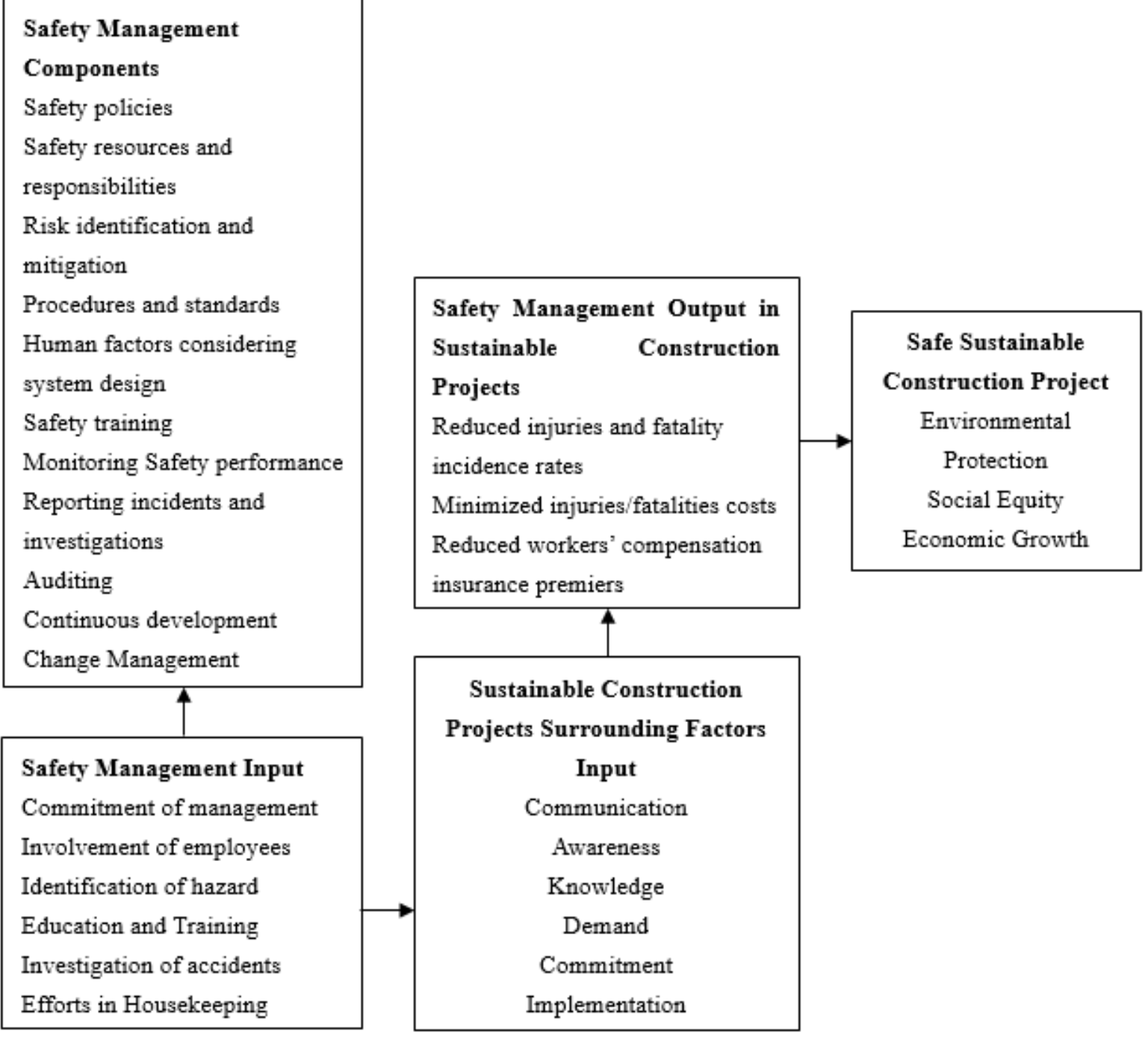

Figure 1. Conceptual Framework for Safety Management in Sustainable Construction Projects

Source: Developed by the Author.

On top of the above, safe sustainable construction projects require specific knowledge, techniques, and tools to attain efficient safety management (Gharehbaghi \& McManus, 2003; Kukoyi \& Adebowale, 2021). Bearing in mind that safe sustainable construction projects must assure compliance to safety policies and regulations and provide effective safety education and training to the construction workers, as such acts would contribute significantly to the attainment of sustainable construction (particularly the social aspects) (Marhavilas et al., 2018; Okoye \& Okolie, 2013). To achieve effective safety management, the concerned individuals in sustainable construction projects should improve and update their knowledge about different fields such as social, economic, political, ethical technical, technological, managerial, cultural, legal /regulatory, organizational, psychological, and educational levels (Ginevičius et al., 2011; Kukoyi \& Adebowale, 2021; Liwång, 2020; Marhavilas et al., 2018). In turn, this will help them not only in eliminating threats but also in 
maintaining a safe sustainable construction environment (Ginevičius et al., 2011; Marhavilas et al., 2018). Also, safe sustainable construction projects require effective safety management to provide efficient safety planning, education, training, and inspection (Park \& Hyeon-Jin, 2013, Marhavilas et al., 2018; Zacchei \& Molina, 2020). Active management is required to delegate tasks, manage change, handle unexpected situations, and deliver desired quality in such projects (Gharehbaghi \& McManus, 2003; Kukoyi \& Adebowale, 2021). Moreover, the availability of adequate facilities in sustainable construction projects could enhance the attainment of reliable safety management, as through these facilities it is possible to promote the coordination, communication, and visibility of construction safety management; precisely predict the risks associated with the sustainable construction process and promote a smooth transition of information among project stakeholders (Li et al., 2021; Liwång, 2020; Marhavilas et al., 2018; Zacchei \& Molina, 2020). In such facilities, it is essential to focus on the specific utilization of sustainable construction safety education, space planning, site evacuation, and safety training (Kukoyi \& Adebowale, 2021; Li et al., 2021; Marhavilas et al., 2018; Zacchei \& Molina, 2020). Nevertheless, an accurate safety monitoring system should be implemented in sustainable construction projects to reduce the likelihood of the occurrence of unplanned safety incidents (Yiu et al., 2018; Zacchei \& Molina, 2020). It is also important to highlight the importance of safety audits and reviews to maintain safe sustainable construction projects (Grote, 2012; Marhavilas et al., 2018; Zacchei \& Molina, 2020). Eventually, remarkable safety management improvements could be attained in sustainable construction projects (Yiu et al., 2018; Marhavilas et al., 2018; Zacchei \& Molina, 2020).

\section{Conclusion}

"Over the years, the construction industry has been intensifying efforts towards finding a reasonable and efficient safety management system geared towards achieving sustainable construction" (Okoye \& Okolie, 2013, P.76). Although sustainable construction projects have an imperative role to play in social, economic, and environmental developments, the likelihood of safety incidents' occurrence is considerably high in such projects (Gunduz \& Almuajebh, 2020; Kukoyi \& Adebowale, 2021; Okoye \& Okolie, 2013; Zhang et al., 2020). This makes safety management in sustainable construction projects very difficult and more challenging (Gunduz \& Almuajebh, 2020; Lee \& Son, 2021; Marhavilas et al., 2018; Zacchei $\&$ Molina, 2020). Hence, the conceptual framework, demonstrated in this study, proposes efficient phases to achieve safe sustainable construction projects. These stages are utilizing safety management components, enriching safety management input, considering the surrounding factors in sustainable construction projects that influence safety management, realizing the desired safety management output, and eventually achieving safe sustainable construction projects (Gunduz \& Almuajebh, 2020; Kim et al., 2020; Kukoyi \& Adebowale, 2021; Lee \& Son, 2021; Liwång, 2020; Marhavilas et al., 2018; Tahmasebinia et al., 2020; Udomsap \& Hallinger, 2020; Zacchei \& Molina, 2020; Zhang et al., 2020). However, although this research contributes sufficiently to the existing safety management and sustainable construction literature, there are three main limitations to be acknowledged. First, this review paper could not capture all existing safety management components, in spite of 
some sources that mentioned their existence, but lacked details that would make them essential for this study. Second, the data collected relied on earlier research, and the results could differ if an empirical study was performed. Third, the produced conceptual framework is applicable for sustainable construction projects, and could not be generalized for other types of projects. Yet, as future work, the results of this research might lead researchers to examine the proposed conceptual framework empirically; establish a similar framework that could integrate safety management components in all sustainable development projects, not only sustainable construction projects; and analyze safety management performance in sustainable construction projects from both the management's and team members' perspectives.

\section{Acknowledgments}

Many thanks to the previous researcher who have contributed their knowledge about safety management and sustainable construction.

\section{References}

Afanasyeva, A., Fedorova, S., \& Yulbarisova, G. (2020). Availability of innovative housing from the perspective of sustainable construction. Availability of Innovative Housing from the Perspective of Sustainable Construction, IOP Conference Series: Materials Science and Engineering, 890(012182), 1-5. https://doi.org/10.1088/1757-899X/890/1/012182

Boyd, D. \& Bentley, D. (2012). A critique of conceptions of design and management in construction projects. Construction Management and Economics, 30(6), 441-454. https://doi.org/10.1080/01446193.2012.688136

Ciegis, R., Kliucininkas, L., \& Ramanauskiene, J. (2011). Assessment of state and tendencies of sustainable development in Lithuania. Management of Environmental Quality: An International Journal, 22(6), 757-768. https://doi.org/10.1108/14777831111170858

El-Sayegh S. M., Manjikian S., Ibrahim A., Abouelyousr A., \& Jabbour, R. (2018). Risk identification and assessment in sustainable construction projects in the UAE. International Journal of Construction Management, 21(4), 1-10. https://doi.org/10.1080/15623599. 2018.1536963

Fukuda-Parr, S., \& Muchhala, B. (2020). The Southern origins of sustainable development goals: Ideas, actors, aspirations. World Development, 126, 104706. https://doi.org/10.1016/j. worlddev.2019.104706

Gharehbaghi, K., \& McManus, K. (2003). Effective Construction Management. Leadership Manage. Eng., 3(1), 54-55. https://doi.org/10.1061/(ASCE)1532-6748(2003)3:1(54)

Ginevičius, T., Kaklauskas, A., \& Kazokaitis, P. (2011). Knowledge Model for Integrated Construction Project Management. Business: Theory and Practice, 12(2), 162-174. https://doi.org/10.3846/btp.2011.17

Greenwood, D., \& Wu, S. (2012). Establishing the association between collaborative working and construction project performance based on client and contractor perceptions. 
Construction Management and Economics, 30(4), 299-308. https://doi.org/10.1080/01446193. 2012.666801

Grote, G. (2012). Safety management in different high-risk domains - All the same? Safety Science, 50(10), 1983-1992. https://doi.org/10.1016/j.ssci.2011.07.017

Gunduz, M., \& Almuajebh, M. (2020). Critical Success Factors for Sustainable Construction Project Management. Sustainability, 12(1990), 1-17. https://doi.org/10.3390/su12051990

Heravi, G., \& Faeghi, S. (2014). Group Decision Making for Stochastic Optimization of Time, Cost, and Quality in Construction Projects. Journal of Computing in Civil Engineering, 28(2), 275-283. https://doi.org/10.1061/(ASCE)CP.1943-5487.0000264

Hewage, K., Gannoruwa, A., \& Ruwanpura, J. (2011). Current status of factors leading to team performance of on-site construction professionals in Alberta building construction projects. Canadian Journal of Civil Engineering, 38(6), 679-689. https://doi.org/10.1139/ $111-038$

Kim, S., Irizarry, J., \& Costa, D. B. (2020). Field Test-Based UAS Operational Procedures and Considerations for Construction Safety Management: A Qualitative Exploratory Study. International Journal of Civil Engineering, 18, 919-933. https://doi.org/10.1007/s40999-02000512-9

Kukoyi, P. O., \& Adebowale, O. J. (2021). Impediments to Construction Safety Improvement. Journal of Engineering, Project, and Production Management, 11(2), 207-214. https://doi.org/10.2478/jeppm-2021-0020

Ladewski, B., \& Al-Bayati, A. (2019). Quality and safety management practices: The theory of quality management approach. Journal of Safety Research, 69, 193-200. https://doi.org/ 10.1016/j.jsr.2019.03.004

Lee, S. H., \& Son, J. (2021). Development of a Safety Management System Tracking the Weight of Heavy Objects Carried by Construction Workers Using FSR Sensors. Applied Sciences, 11(4), 1-15. https://doi.org/10.3390/app11041378

Li, H., Lu, M., Hsu, S., Gray, M., \& Huang, T. (2015). Proactive behavior-based safety management for construction safety improvement. Safety Science, 75, 107-117. https://doi.org/10.1016/j.ssci.2015.01.013

Li, S., Zhang, D., \& Tian, C. (2021). Research on the Application of BIM Technology Based on Information Technology in Construction Engineering Safety Management. Journal of Physics: Conference Series, 1915(022094), 1-5. https://doi.org/10.1088/1742-6596/1915/2/ 022094

Liwång, H. (2020). Safety management module to create social sustainability skills. International Journal of Sustainability in Higher Education, 21(4), 717-732. https://doi.org/ 10.1108/IJSHE-09-2019-0264.

Loushine, T. W., Hoonakker, P. L. T., Carayon, P., \& Smith, M. J. (2006). Quality and Safety 
Management in Construction. Total Quality Management, 17(9), 1171-1212. https://doi.org/ $10.1080 / 14783360600750469$

Marhavilas, P., Koulouriotis, D., Nikolaou, I., \& Tsotoulidou, S. (2018). International Occupational Health and Safety Management-Systems Standards as a Frame for the Sustainability: Mapping the Territory. Sustainability, 10(3663), 1-26. https://doi.org/ 10.3390/su10103663

Mensah, S., Ayarkwa, J., \& Nani, G. (2018). A theoretical framework for conceptualizing contractors' adaptation to environmentally sustainable construction. International Journal of Construction Management, 801-811. https://doi.org/10.1080/15623599.2018.1484860

Moher, R., Liberati, A., Tetzlaff, J., Altman, D. G., The PRISMA Group, 2009. Preferred reporting items for systematic reviews and meta-analyses: the PRISMA statement. PLoS Med. 6 (7), 1-6. https://doi.org/10.1371/journal.pmed.1000097.g001

Okoye, P. U., \& Okolie, K. C. (2013). Social Approach to Sustainable Construction Practices Through Safety Culture. International Journal of Engineering Research and Development, $6(11), 76-83$.

Petticrew, M., \& Roberts, H. (2006). Systematic Reviews in the Social Sciences. A Practical Guide. Oxford: Blackwell.

Remington-Doucette, S., \& Musgrove, S. (2015). Variation in sustainability competency development according to age, gender, and disciplinary affiliation: Implications for teaching practice and overall program structure. International Journal of Sustainability in Higher Education, 16(4), 537-575. https://doi.org/10.1108/IJSHE-01-2013-0005

Robichaud, L. B., \& Anantatmula, V. S. (2011). Greening Project Management Practices for Sustainable Construction. Journal of Management in Engineering, 27(1), 48-57. https://doi.org/10.1061/(ASCE)ME.1943-5479.0000030

Sachs, J. (2012). From Millennium Development Goals to Sustainable Development Goals. The Lancet, 379(9832), 2206-2211. https://doi.org/10.1016/S0140-6736(12)60685-0

Secundo, G., Ndou, V., Vecchio, P., \& De Pascale, G. (2020). Sustainable development, intellectual capital and technology policies: A structured literature review and future research agenda. Technological Forecasting and Social Change, 153, 119917. https://doi.org/ 10.1016/j.techfore.2020.119917

Tahmasebinia, F., Sepasgozar, S. M. E., Shirowzhan, S., Niemela, M., Tripp, A., Nagabhyrava, S., Ko, K., Mansuri, Z., \& Alonso-Marroquin, F. (2020), "Criteria development for sustainable construction manufacturing in Construction Industry 4.0: Theoretical and laboratory investigations", Construction Innovation, 20(3), 379-400. https://doi.org/10.1108/ CI-10-2019-0103

Udomsap, A. D., \& Hallinger, P. (2020). A bibliometric review of research on sustainable construction, 1994-2018. Journal of Cleaner Production, 254(120073), 1-9. https://doi.org/10.1016/j.jclepro.2020.120073 


\section{Macrothink}

International Journal of Global Sustainability

ISSN 1937-7924 2021, Vol. 5, No. 1

Wiek, A., Withycombe, L., \& Redman, C. (2011). Key competencies in sustainability: a reference framework for academic program development. Sustainability Science, 6(2), 203-218. https://doi.org/10.1007/s11625-011-0132-6

Yiu, N. S. N., Sze, N. N., \& Chan, D. W. M. (2018). Implementation of safety management systems in Hong Kong construction industry - A safety practitioner's perspective. Journal of Safety Research, 64, 1-9. https://doi.org/10.1016/j.jsr.2017.12.011

Zacchei, E., \& Molina, J. L. (2020). Reviewing Arch-Dams' Building Risk Reduction Through a Sustainability-Safety Management Approach. Sustainability, 12(392), 1-21. https://doi.org/10.3390/su12010392

Zhang, R., Wang, Z., Tang, Y., \& Zhang, Y. (2020). Collaborative Innovation for Sustainable Construction: The Case of an Industrial Construction Project Network. IEEE Access, 8, 41403-41417. https://doi.org/10.1109/ACCESS.2020.2976563

\section{Copyright Disclaimer}

Copyright for this article is retained by the author(s), with first publication rights granted to the journal.

This is an open-access article distributed under the terms and conditions of the Creative Commons Attribution license (http://creativecommons.org/licenses/by/4.0/). 